\title{
A cross-sectional study on knowledge, attitude and practice of infant feeding practices among reproductive age women attending outpatient department of obstetrics and gynecology in Dr. B. R. Ambedkar Medical College and Hospital, Bengaluru-45
}

\author{
Bushra Jabeen $^{1}$, S. P. Suryanarayana ${ }^{2}$, M. Puttaswamy ${ }^{3}$
}

\begin{abstract}
${ }^{1}$ Post graduate student, ${ }^{2}$ Professor and Head of Department, ${ }^{3}$ Assistant Professor in Bio Statistics, Department of Community Medicine, Dr. B. R. Ambedkar Medical College, Bengaluru, Karnataka, India
\end{abstract}

Received: 12 June 2018

Revised: 09 July 2018

Accepted: 10 July 2018

\section{*Correspondence:}

Dr. Bushra Jabeen,

E-mail: dr.bushra.jbn@gmail.com

Copyright: (C) the author(s), publisher and licensee Medip Academy. This is an open-access article distributed under the terms of the Creative Commons Attribution Non-Commercial License, which permits unrestricted non-commercial use, distribution, and reproduction in any medium, provided the original work is properly cited.

\section{ABSTRACT}

Background: Adequate nutrition during infancy and early childhood is essential to ensure the growth, health, and development of children to their full potential. Lack of knowledge, wrong attitude and faulty practices among mothers in some aspects of infant feeding can lead to infant mortality. Thus, appropriate infant feeding practices and following recommended practice of exclusive breastfeeding could help in improvement of health of child and mother and also improve IMR. The objective of the study was assessment of knowledge, attitude and practice of infant feeding practices among reproductive age women.

Methods: An institutional based, descriptive cross sectional study was conducted among reproductive age group (15 to 49 years) women attending OPD of OBGY department for various reasons. A semi structured questionnaire along with software tools like EpiInfo7, MS Excel and SPSS version 23 are used for data analysis.

Results: A total of $98.5 \%$ of women consider breast milk as best nutrition and $77 \%$ were aware regarding exclusive breastfeeding. Weaning was most commonly started with mashed cereals $(68.5 \%)$ with other food items at lower percentage. Participants are aware that breastfeeding is beneficial to both mother and child, and should not be avoided in any condition unless advised by treating doctor.

Conclusions: Through the mothers under study had adequate knowledge regarding feeding practice but in this study it was observed that the appropriate practice worsens with increasing parity of mother.

Keywords: Infant feeding, Breastfeeding, Weaning, Reproductive age women

\section{INTRODUCTION}

Adequate nutrition during infancy and early childhood is essential to ensure the growth, health, and development of children to their full potential. Proper breastfeeding practices are effective ways for reducing childhood morbidity and mortality. ${ }^{1}$ IMR is regarded as a sensitive indicator of health status of community. IMR of India is $34 / 1000$ live births, of Karnataka is 24/1000 live births as per sample registration system (SRS 2016). ${ }^{2,3}$
Many mothers understand the importance of breastfeeding, others are less knowledgeable on the benefits of breastfeeding and weaning.

WHO recommends mothers worldwide to exclusively breastfeed infants for the child's first six months to achieve optimal growth, development and health. Thereafter, they should be given nutritious complementary foods and continue breastfeeding up to the age of two years or beyond. ${ }^{4}$ 
Studies have shown that lack of knowledge, wrong attitude and faulty practices among mothers in some aspects of infant feeding are the most evitable cause of infant mortality. Thus, appropriate infant feeding practices and following recommended practice of exclusive breastfeeding could help in improvement of health of child and mother and also improve IMR.

\section{Objective}

Assessment of knowledge, attitude and practice of infant feeding practices among reproductive age women.

\section{METHODS}

An institutional based, descriptive cross sectional study was conducted among reproductive age group (15 to 49 years) women attending OPD of OBGY department. Verbal consent was obtained after the participants had been informed about the study objectives. Duration of study was 2 months from $5^{\text {th }}$ December 2017 to $10^{\text {th }}$ February 2018.

Sample size was determined by purposive sampling depending on average number of women visiting Obstetrics and Gynecology Outpatient Department. Thus, 200 women falling into inclusion criteria were involved in the study.

Women in their reproductive age group, willing to participate in the study were included in the study whereas women consulting the OPD for severe illness and unmarried women were not included in the study.

A semi structured questionnaire was used to interview the participants, and Face to face interview was conducted. The responses were entered in EpiInfo7 software and further analysis was conducted using MS Excel, EpiInfo7 and SPSS software.

\section{RESULTS}

A total of 200 respondents were interviewed for the study of which $64 \%$ mothers had at least completed high school level education. The age of participants ranged from 19 to 42 years, wherein majority belonged to age group 25 to 34 years $(53.5 \%)$ and most of them living in nuclear type of family $(50.5 \%)$. A total of $98.5 \%$ of women consider breast milk as best nutrition and $77 \%$ of women were aware regarding Exclusive breastfeeding, most of them acquired knowledge about it from health institute (66.5\%). Among the participants $79.5 \%$ were housewives. Weaning was rightly understood by $60.5 \%$ of mothers and most common food item used initially to start weaning was mashed cereals $(68.5 \%)$.

Most of the participants are aware that breastfeeding increases immunity of child $(89 \%)$ and intelligence (22\%), for mothers it strengthens their bond with child $(89 \%)$ and protects from cancer $(26 \%)$. And according to
$59.5 \%$ of the participants breastfeeding should not be avoided in any condition.

Table 1 : Participants description.

\begin{tabular}{|lll|}
\hline Parameter & N & Percentage (\%) \\
\hline Educational status & & \\
\hline Illiterate & 26 & 13 \\
\hline Primary school & 16 & 8 \\
\hline Middle school & 30 & 15 \\
\hline High school & 81 & 40.5 \\
\hline Intermediate & 26 & 13 \\
\hline Graduate & 18 & 9 \\
\hline Honorium & 3 & 1.5 \\
\hline Age at marriage (in years) & \\
\hline 15-20 & 155 & 77.5 \\
\hline 21-25 & 39 & 19.5 \\
\hline 26-30 & 6 & 3 \\
\hline Pregnancy status & & \\
\hline Present & 154 & 77 \\
\hline Absent & 46 & 23 \\
\hline Primigravida & 29 & 18.8 \\
\hline Multigravida & 123 & 79.9 \\
\hline Type of family & & \\
\hline Nuclear & 101 & 50.5 \\
\hline Three generation & 19 & 9.5 \\
\hline Joint & 80 & 40 \\
\hline
\end{tabular}

Majority of the Muslim participants (67.8\%) denied following exclusive breastfeeding as there was introduction of honey water (68\%) soon after birth of baby. Table 2 Shows the various parameters used to assess knowledge of the participants.

Table 2: Knowledge assessment details.

\begin{tabular}{|c|c|c|}
\hline Variable & No. & $\begin{array}{l}\text { Percentage } \\
(\%)\end{array}$ \\
\hline \multicolumn{3}{|c|}{$\begin{array}{l}\text { When should breastfeeding after delivery be } \\
\text { started? }\end{array}$} \\
\hline Immediately within 1 hour & 167 & 83.5 \\
\hline 2-24 hours & 18 & 9 \\
\hline After 24 hours & 5 & 2.5 \\
\hline \multicolumn{3}{|c|}{ For how long is exclusive breastfeeding needed? } \\
\hline About 6 months & 125 & 62.5 \\
\hline Beyond 6 months & 40 & 20 \\
\hline \multicolumn{3}{|c|}{ Suitable age of baby to start weaning- } \\
\hline 4-6 months & 36 & 18 \\
\hline More than 6 months & 127 & 63.5 \\
\hline \multicolumn{3}{|c|}{ Age for complete weaning from breast milk- } \\
\hline At 1 year & 47 & 23.5 \\
\hline 1.5 years & 55 & 27.5 \\
\hline 2 years & 62 & 31 \\
\hline More than 2 years & 13 & 6.5 \\
\hline
\end{tabular}

Participants have positive attitude towards EBF as they consider it better (92\%) than artificial feeding. And $75.5 \%$ of participants prefer feeding breast milk for first 6 months. 
Table 3: Attitude assessment details.

\begin{tabular}{|c|c|c|}
\hline Variable & No. & Percentage (\%) \\
\hline \multicolumn{3}{|c|}{$\begin{array}{l}\text { Do you agree that only EBF is enough for child up } \\
\text { to } 6 \text { months? }\end{array}$} \\
\hline Agree & 164 & 82 \\
\hline Disagree & 30 & 15 \\
\hline Don't know & 6 & 3 \\
\hline \multicolumn{3}{|c|}{$\begin{array}{l}\text { Do you agree that child less than } 6 \text { month who is } \\
\text { exclusively breastfed is healthier than child who } \\
\text { takes additional food? }\end{array}$} \\
\hline Yes & 155 & 77.5 \\
\hline No & 18 & 9 \\
\hline I don't know & 27 & 13.5 \\
\hline
\end{tabular}

All the participants have exclusively breastfed their children for at least 3 to 4 months $(73.5 \%)$ whereas $58.3 \%$ of participants have continued breastfeeding beyond 6 months.

Table 3 Shows the various parameters used to assess attitude of the participants. Table 4 Shows the various parameters used to assess practice of the participants.

Table 4: Practice assessment details.

\begin{tabular}{|c|c|c|}
\hline Variable & No. & Percentage (\%) \\
\hline \multicolumn{3}{|c|}{$\begin{array}{l}\text { When did you start breastfeeding after delivering } \\
\text { your last child? }\end{array}$} \\
\hline Immediately & 130 & 77.4 \\
\hline 2 to 24 hours & 27 & 16.1 \\
\hline After 24 hour & 11 & 6.5 \\
\hline \multicolumn{3}{|c|}{ How frequently did you breastfed your last child? } \\
\hline On demand & 137 & 81.5 \\
\hline Regularly & 26 & 15.5 \\
\hline Randomly & 5 & 3.0 \\
\hline \multicolumn{3}{|c|}{ Feeding pattern/at a time } \\
\hline One side & 46 & 27.4 \\
\hline Both side & 122 & 72.6 \\
\hline
\end{tabular}

Response for discarding of colostrum in \%

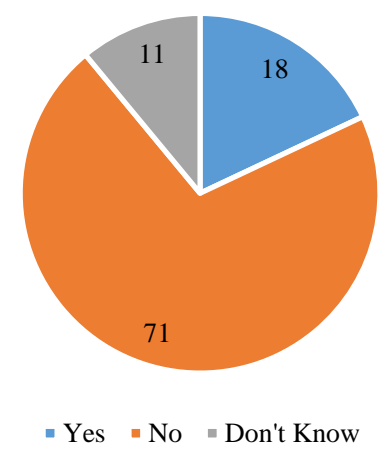

Figure 1: Response towards discarding of colostrum.

Figure 1, 2 shows the pie chart for colostrum feeding: attitude and practice respectively.
Just $28 \%$ of the participants did not follow exclusive breastfeeding practice due to various reasons mentioned below.

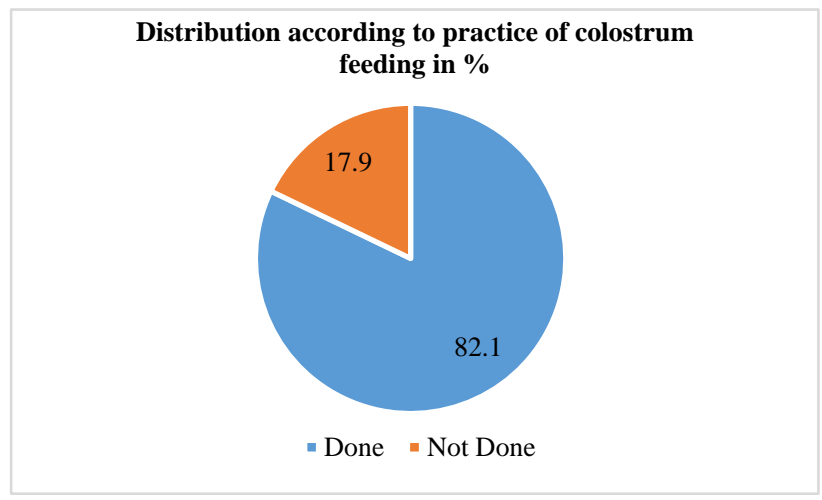

Figure 2: Practice of colostrum feeding.

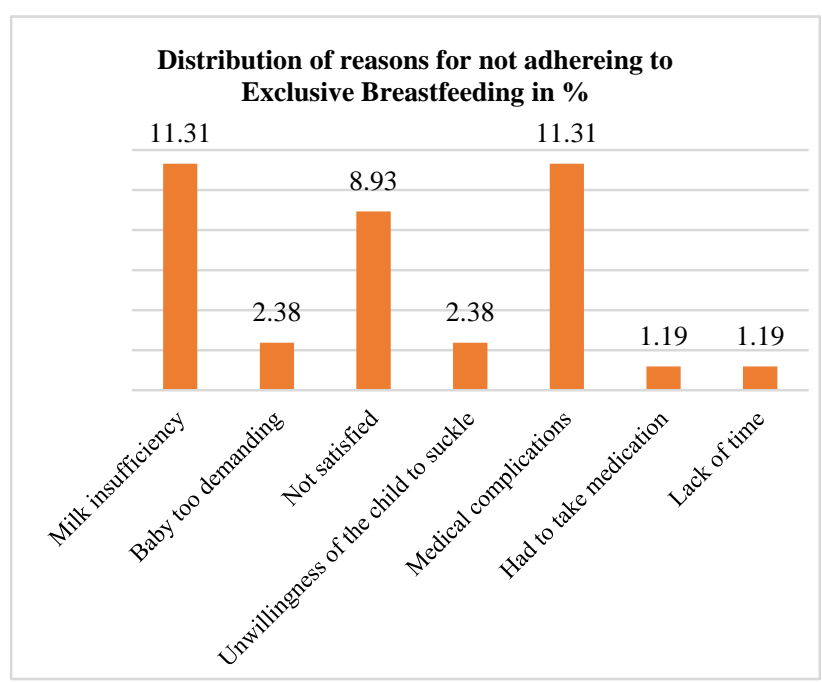

Figure 3: Bar graph representing various reasons for not being adhered to exclusive breastfeeding.

Distribution of Problems faced during Breastfeeding in \%

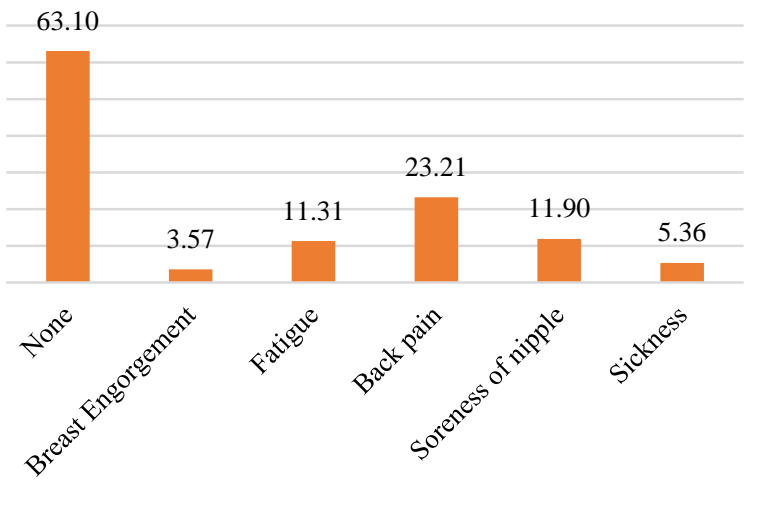

Figure 4: Bar graph representing various problems faced during breastfeeding. 


\section{DISCUSSION}

A study conducted by Motee et al, the prevalence of breastfeeding practice in Mauritius has risen from $72 \%$ in 1991 to $93.4 \%$, while only $17.9 \%$ breastfed their children exclusively for the first 6 months, and the mean duration of EBF (exclusive breastfeeding) is 2.10 months. Complementary feeding was more commonly initiated around 4-6 months $(75.2 \%)^{.1}$

In a KAP study conducted in Egypt rural area also showed that the majority of the mothers had good knowledge about the advantages of breastfeeding for child. As regards weaning, majority (92.5\%) of the mothers defined weaning as breastfeeding cessation. Most of the mothers $(94.8 \%)$ agreed that breastfeeding protect child from infection, $96.1 \%$ agreed that it is the healthiest for infant, and $83.4 \%$ agreed that breastfeeding should be avoided during mother's illness. About $84 \%$ initiated breastfeeding immediately after delivery, and $42.7 \%$ of the studied mothers offered pre-lacteal feeds to baby before lactation. About thirty quarters (74.2\%) of mothers fed colostrum. ${ }^{5}$

And a similar study from Ajmer district has shown the average knowledge score of urban mother in breast feeding and weaning to be $61.6 \%$ and $64.0 \%$ respectively. Attitude scores on breastfeeding among the groups were $81.8 \%$ which was better in rural mothers whereas attitude scores about weaning among the groups was average $50 \%$. The average score $83.3 \%$ of breast feeding practices among urban mother, similar observation was made for weaning practices in which average score of urban mother $(86.8 \%){ }^{6}$

A descriptive cross-sectional study conducted in Ethiopia also concluded that majority of mothers knew about EBF and had a positive attitude towards EBF but did not know the recommended duration or that EBF is sufficient for six months. ${ }^{7}$

In this study also similar findings were observed, total of $98.5 \%$ of women consider breast milk as best nutrition and $77 \%$ of women were aware regarding exclusive breastfeeding. Weaning was rightly understood by $60.5 \%$ of mothers and most common food item used initially to start weaning was mashed cereals $(68.5 \%)$.

Most of the participants are aware that breastfeeding increases immunity of child (89\%) and intelligence (22\%), and among mothers it strengthens their bond with child (89\%) and also protects from cancer (26\%).

Attitude towards EBF was good (92\%). And $75.5 \%$ of participants prefer feeding breast milk for first 6 months. And some of the reasons for not following recommended duration of exclusive breastfeeding were: medical complications due to which child was being treated in NICU and milk insufficiency.
A study conducted in Mexico also showed findings where in participants, including fathers, believed that breast milk was the best and healthiest for the baby (60\%), and that breast milk had nutritional properties that help the infant's immune system (17\%). Participants also mentioned benefits for the mother, such as prevention of breast cancer. However, participants also mentioned the fear that the infant would not be full with breast milk alone $(40 \%)$, and that water was necessary in addition to breast milk for thirst $(17 \%){ }^{8}$

\section{CONCLUSION}

Adequate knowledge was assessed from mothers regarding breastfeeding and weaning practice. In this study it was also observed that parity was indirectly proportional to breastfeeding practice and the initiation of weaning was early. And colostrum feeding was regarded as good practice which can improve health of child. It is recommended to encourage mothers to follow correct feeding practice of infants despite of parity, by strengthening health education and community participation.

Funding: No funding sources

Conflict of interest: None declared

Ethical approval: The study was approved by the Institutional Ethics Committee

\section{REFERENCES}

1. Motee A, Ramaswamy D, Gunsam PP, Jeewon R. An Assessment of the Breastfeeding Practices and Infant Feeding Pattern among Mothers in Mauritius. J Nutr Metabol. 2013;243852:8

2. National family health survey-4 2015-16. Available at: http://www.nfhsindia.org. Accessed on 03 June 2018.

3. SRS Bulletin; sample registration system; registrar general India; vol 51 (1); ISSN 0971-3549.

4. WHO- Exclusive breastfeeding recommendations. Available at: http://www.who.int/mediacentre/news/ statements/2011/breastfeeding_20110115/en/.

Accessed on 01 June 2018.

5. Mohammed ES, Ghazawy ER, Hassan EE. Knowledge, Attitude, and Practices of Breastfeeding and Weaning Among Mothers of Children up to 2 Years Old in a Rural Area in El-Minia Governorate, Egypt. J Family Med Prim Care. 2014;3(2):136-40.

6. Karnawat D, Karnawat BS, Joshi A, Kohli GK. Knowledge, attitude \& practices about infant feeding among mothers of urban \& rural areas of Ajmer district. J Med Res. 2015;1(3):90-4.

7. Tadele N, Habta F, Akmel D, Deges E. Knowledge, attitude and practice towards exclusive breastfeeding among lactating mothers in Mizan Aman town, Southwestern Ethiopia: descriptive cross-sectional study. Int Breastfeeding J. 2016;11:3. 
8. Swigart TM, Bonvecchio A, Théodore FL, Zamudio-Haas S, Villanueva-Borbolla MA, Thrasher JF. Breastfeeding practices, beliefs, and social norms in low-resource communities in Mexico: Insights for how to improve future promotion strategies. PLoS ONE. 2017;12(7):e0180185.
Cite this article as: Jabeen B, Suryanarayana SP, Puttaswamy M. A cross-sectional study on knowledge, attitude and practice of infant feeding practices among reproductive age women attending outpatient department of obstetrics and gynecology in Dr. B. R. Ambedkar Medical College and Hospital, Bengaluru-45. Int J Community Med Public Health 2018;5:4023-7. 